\section{International Journal of Medical Research and Review}

2020 Volume 8 Number 6 November-December

\title{
Prevalence of overweight and obesity among adolescents in South Indian population
}

\author{
Gayathri D. ${ }^{1 *}$, Syamily ${ }^{2}$, Kulandaivel M. ${ }^{3}$ \\ DOI: https://doi.org/10.17511/ijmrr.2020.i06.05 \\ 1* Gayathri D., Assistant Professor, Department of Pediatrics, Sri Venkateshwaraa Medical College and Research center, Ariyur, Pondicherry, \\ India. \\ 2 Syamily, Post-Graduate, Department of Pediatrics, Sri Venkateshwaraa Medical College and Research center, Ariyur, Pondicherry, India. \\ ${ }^{3}$ Kulandaivel M., Professor, Department of Pediatrics, Sri Venkateshwaraa Medical College and Research center, Ariyur, Pondicherry, India.
}

Introduction: Childhood obesity is one of the global public health challenges of the 21st century, affecting every country in the world. Globally, in just 40 years the prevalence of obesity has raised more than 10-fold from 11 million to 124 million school-age children. Material and Methods: This study is a school-based cross-sectional study. The study population is 150 children from 11-14 years old school children from a selected private school in urban Pondicherry. Result: In the present study it was observed the prevalence of overweight and obesity shows that the prevalence of overweight is $18 \%(\mathrm{~N}=27)$ and Obesity is $6 \%(\mathrm{~N}=9)$ based on BMI. Overweight and Obesity is an emerging major health problem in school children in our Country. Conclusion: In the present study, there is an increase in the prevalence of overweight /obesity in school children.

Keywords: Overweight, Obesity, School Children, Prevalence, Adolescent, South India

Corresponding Author

Gayathri D., Assistant Professor, Department of Pediatrics, Sri Venkateshwaraa Medical College and Research center, Ariyur, Pondicherry, India.

Email: dr.gayudurai@gmail.com
How to Cite this Article

Gayathri D, Syamily, Kulandaivel M. Prevalence of overweight and obesity among adolescents in South Indian population. Int J Med Res Rev. 2020;8(6):404-409.

Available From

https://ijmrr.medresearch.in/index.php/ijmrr/article/ view/1226
To Browse

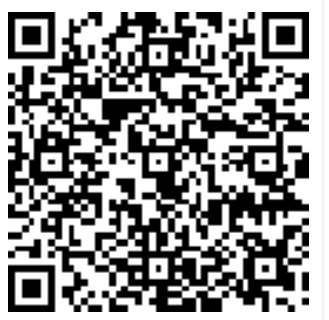

Manuscript Received 2020-11-13

Conflict of Interest No
Review Round 1 2020-11-16

Funding $\mathrm{Nil}$

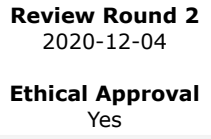

Review Round 3

Plagiarism X-checker $8 \%$
Accepted 2020-12-23

Note

(C) 2020 by Gayathri D., Syamily, Kulandaivel M. and Published by Siddharth Health Research and Social Welfare Society. This is an Open Access article licensed under a Creative Commons Attribution 4.0 International License https://creativecommons.org/licenses/by/4.0/ unported [CC BY 4.0]. 


\section{Introduction}

Childhood obesity is one of the global public health challenges of the 21st century, affecting every country in the world. Globally, in just 40 years the prevalence of obesity has raised more than 10 -fold from 11 million to 124 million in school-age children and adolescents according to a 2016 estimate [1]. With modernization, overweight/obesity is also rapidly growing in many developing countries. The world today faces a double burden of malnutrition which includes both undernutrition and overweight.

All countries have framed a set of global targets for halting the increase in overweight/obesity, its main target is to that no increase in overweight among children under age 5, school-age children, or adolescents by 2025. A study conducted in 2016 reported that the prevalence of obesity and overweight was $15.8 \%$ among urban and $26 \%$ among the rural children in India. Dietary habits including high energy-dense foods and lack of physical activity were the main risk factor [2].

The weight of children tracked from childhood to adulthood, children who are overweight or obese end up being obese in their adulthood. Considering that prevention efforts are always directed by findings from several studies [3]. Excess fat in childhood is a risk factor for later adult disease and is related to impaired health during childhood itself.

Obesity is expressed in terms of Body Mass Index, Waist circumference, Waist to Hip Ratio, and Skinfold thickness, Neck circumference. According to a study conducted in 2011, the waist circumference of the Indian children was higher than age and sex-matched European children [4].

Due to the difficulty in the treatment of obesity in adults and many long-term side effects of childhood obesity, prevention of childhood obesity has now been recognized as a public health priority [5]. In India, the emergence of childhood obesity presents a cause for concern because of recent changes in lifestyle and economic development [6].

Obesity is now emerging as a common nutritional disorder. It usually results when food consumption is more than one's physiological needs [7]. National Nutrition Monitoring Bureau (NNMB) data observed high obesity levels in urban slums indicating that obesity is now affecting the urban poor also [8]. Complications of adult obesity are made worse if obesity begins in childhood [9].
In this study, the prevalence of overweight and obesity in 11-14 years of school children in a private school in Urban Pondicherry is estimated using BMI, Waist circumference (WC), and Waist Height Ratio (WHtR).

\section{Methodology}

Study setting: This study is a school-based crosssectional study done among 11-14 years old school children from a selected private school in urban Pondicherry.

Duration: The study was carried out for 6 months from June 2019 to December 2019. The study population was selected randomly and the sample size was calculated to be using Open Epi Version 3.01 (formula Z2pq/d2, where " $p$ " was considered the maximum of $13.04 \%$, absolute precision of $5 \%$, $95 \%$ confidence interval, and alpha error of $5 \%$. [10]

\section{Inclusion criteria:}

- Children of age group 11-14 years present during the study.

\section{Exclusion criteria:}

- Children who lived in Pondicherry less than 1 year before the study

- Children with clinically diagnosed chronic illness, physical and mental defects.

Study procedure: The sample population was selected from one private school in Pondicherry. Students of age group 11- 14 years were included in this study. The study was conducted after getting permission from school management through the proper channel. The study was carried out during break time after getting consent from participants. A performa was used for collecting requisite information from students.

Performa included Personal details, physical activities; screen viewing time (watching television, playing computer and video games), Food habit (healthy or unhealthy/junk food), and meals frequency was taken into consideration. Portable stadiometer used for measuring height Portable weighing machine used for measuring weight. Waist circumference, hip circumference was measured using a non-stretchable elastic tape.

In this study, 150 children under the age of $11-14$ were enrolled and this study was approved by the ethics committee (Ref: SVMCH / IEC/2018 - NOV 
/IEC 06) Permission was obtained from the school principal, and consent from Participants of the study. The date was tabulated and analyzed with descriptive method, mean, and standard deviation.

\section{Results}

Table-1: Age-wise distribution.

\begin{tabular}{|l|l|l|}
\hline \multicolumn{1}{|c|}{ Age } & \multicolumn{1}{c|}{ Frequency } & \multicolumn{1}{c|}{ Percent } \\
\hline 11 & 36 & 24.0 \\
\hline 12 & 37 & 24.7 \\
\hline 13 & 37 & 24.7 \\
\hline 14 & 40 & 26.7 \\
\hline Total & 150 & 100.0 \\
\hline
\end{tabular}

The participants in the study were evenly distributed from 11 to 14 years with an almost equal number of the study population in each age.

Table-2: Sex wise distribution.

\begin{tabular}{|l|l|l|}
\hline \multicolumn{1}{|c|}{ Sex } & \multicolumn{1}{c|}{ Frequency } & \multicolumn{1}{c|}{ Percent } \\
\hline Boys & 67 & 44.7 \\
\hline Girls & 83 & 55.3 \\
\hline Total & 150 & 100.0 \\
\hline
\end{tabular}

In the present study, girls dominated the study population with $55.3 \%$ and boys were 44 . $7 \%$.

Table-3: Studying classes.

\begin{tabular}{|l|l|l|}
\hline \multicolumn{1}{|c|}{ Class } & \multicolumn{1}{c|}{ Frequency } & \multicolumn{1}{c|}{ Percent } \\
\hline 6th & 35 & 23.3 \\
\hline 7th & 39 & 26.0 \\
\hline 8 th & 38 & 25.3 \\
\hline 9th & 38 & 25.3 \\
\hline Total & 150 & 100.0 \\
\hline
\end{tabular}

In the present study, the strength of students was evenly distributed in each age so as it was reflected in the class of standard from 6th to 9 th.

Table-4: Distribution of students involved in various games which include Indoor or Outdoor games or both.

\begin{tabular}{|l|l|l|}
\hline \multicolumn{1}{|c|}{ Games } & \multicolumn{1}{c|}{ Frequency } & \multicolumn{1}{c|}{ Percent } \\
\hline Both & 81 & 54.0 \\
\hline Indoor & 21 & 14.0 \\
\hline Outdoor & 48 & 32.0 \\
\hline Total & 150 & 100.0 \\
\hline
\end{tabular}

In the present study, it was found that more students had both indoor and outdoor activity with $54.0 \%$.

Table-5: Distribution of students involved in household activities.

\begin{tabular}{|l|l|l|}
\hline \multicolumn{1}{|c|}{ Household activities } & Frequency & \multicolumn{1}{c|}{ Percentage } \\
\hline Yes & 74 & 49.3 \\
\hline No & 76 & 50.7 \\
\hline Total & 150 & 100 \\
\hline
\end{tabular}

In the present study, it was observed that less than $50 \%$ of the students were involved in the household activities though girls dominated in the study population strength.

Table-6: Distribution of students who are spending time watching Television/ laptop/ mobile phones given in hours per day.

\begin{tabular}{|l|l|l|}
\hline \multicolumn{1}{|c|}{ Screen viewing time (hours/day) } & Frequency & Percent \\
\hline Nil & 25 & 16.7 \\
\hline 1 hour & 64 & 42.7 \\
\hline 2 hours & 47 & 31.3 \\
\hline 3 hours & 14 & 9.3 \\
\hline Total & 150 & 100.0 \\
\hline
\end{tabular}

In the present study concerning the duration of time spent on TV and mobile were 1-2 hrs was more than $70 \%$.

Table-7: Distribution of students based on their food type which includes vegetarian (V) or non-vegetarian (NV).

\begin{tabular}{|l|l|l|}
\hline \multicolumn{1}{|c|}{ Food type } & \multicolumn{1}{c|}{ Frequency } & \multicolumn{1}{c|}{ Percent } \\
\hline NV & 141 & 94.0 \\
\hline V & 9 & 6.0 \\
\hline Total & 150 & 100.0 \\
\hline
\end{tabular}

In the present study, $94 \%$ of the students were non-vegetarians and only $6 \%$ were vegetarians.

Table-8: Distribution of students based on their frequency of eating meals.

\begin{tabular}{|l|l|l|}
\hline \multicolumn{1}{|c|}{ Meals } & \multicolumn{1}{c|}{ Frequency } & \multicolumn{1}{c|}{ Percent } \\
\hline 3 times & 129 & 86.0 \\
\hline 4 times & 21 & 14.0 \\
\hline Total & 150 & 100.0 \\
\hline
\end{tabular}

In the present study, it was found that the convention of three meals was dominant with $86 \%$ and only $14 \%$ with more than three meals.

Table-9: Distribution of students based on their frequency of dining out in a week.

\begin{tabular}{|l|l|l|}
\hline \multicolumn{1}{|c|}{ Dining out (times per week) } & Frequency & Percent \\
\hline Nil & 29 & 19.3 \\
\hline Once & 58 & 38.7 \\
\hline Twice & 37 & 24.7 \\
\hline Thrice & 14 & 9.3 \\
\hline Four times & 12 & 8.0 \\
\hline Total & 150 & 100.0 \\
\hline
\end{tabular}


In the present study, it was found more than $70 \%$ of the students dine outside once or twice a week and only $19.3 \%$ of the students do not dine outside at all.

Table-10: Distribution of students based on their consumption of unhealthy snacks (Pizza, burger, ice cream, shawarma) and aerated drinks (like Pepsi, coke) in a day.

\begin{tabular}{|l|l|l|}
\hline \multicolumn{1}{|c|}{ Unhealthy snacks } & Frequency & \multicolumn{1}{c|}{ Percent } \\
\hline Yes & 66 & 44.0 \\
\hline No & 84 & 56.0 \\
\hline Total & 150 & 100.0 \\
\hline
\end{tabular}

In the present study, it was found less than $50 \%$ that is only $44 \%$ of the students found to eat unhealthy food outside, and more than $50 \%$ that is $56 \%$ do not eat unhealthy food.

Table-11: Distribution of students as Normal/Overweight/Obese based on BMI.

\begin{tabular}{|l|l|l|}
\hline & \multicolumn{1}{|c|}{ Frequency } & \multicolumn{1}{c|}{ Percent } \\
\hline Normal & 114 & 76.0 \\
\hline Overweight & 27 & 18.0 \\
\hline Obese & 9 & 6.0 \\
\hline Total & 150 & 100.0 \\
\hline
\end{tabular}

In the present study, the number of students who were overweight is $27(18 \%)$, Obese is $9(6 \%)$ and normal BMI is 114 (76\%).

Table-12: Distribution of students based on waist circumference into normal and obese.

\begin{tabular}{|l|l|l|}
\hline & \multicolumn{1}{|c|}{ Frequency } & \multicolumn{1}{c|}{ Percent } \\
\hline Normal & 116 & 77.3 \\
\hline Obese & 34 & 22.7 \\
\hline Total & 150 & 100.0 \\
\hline
\end{tabular}

Table-13: Distribution of students based on waist/height ratio into normal and obese.

\begin{tabular}{|l|l|l|}
\hline & \multicolumn{1}{|c|}{ Frequency } & \multicolumn{1}{c|}{ Percent } \\
\hline Normal & 122 & 81.3 \\
\hline Obese & 28 & 18.7 \\
\hline Total & 150 & 100.0 \\
\hline
\end{tabular}

In the present study based on waist circumference, $22.7 \%$ were obese, and based on waist/height ratio was $18.7 \%$.

\section{Discussion}

The results of the present study conducted in 11 to 14 years old school children in a private school of urban Pondicherry to estimate the prevalence of overweight and obesity shows that the prevalence of overweight is $18 \%(\mathrm{~N}=27)$ and Obesity is $6 \%$
$(\mathrm{N}=9)$ based on BMI. The prevalence of obesity in the present study is on par with the study conducted by Vishnu Prasad et al [11] in 2015 where obesity was $4.3 \%$ conducted in Pondicherry whereas the prevalence of overweight was $9.7 \%$, found to be lesser than the present study. Similarly, a study conducted in Kerala showed that prevalence was $3 \%$ for boys, $5.3 \%$ for girls. Prevalence of obesity $(7.5 \%)$, overweight (21.9\%) were highest among high-income group and lowest $(1.5 \%$ and $2.5 \%$ ) among low-income group [12]. A study conducted among adolescent school children in South Karnataka has shown the prevalence of overweight and obesity to be $9.9 \%$ and $4.8 \%$ respectively [13].

While the estimation of obesity based on waist/height ratio and waist circumference based on the study done by Amit Sohani et al [14] in the year 2015 , the prevalence of overweight and obesity is increased to $18.7 \%$ and $22.7 \%$ respectively. It is noted that such studies have not been conducted using all three parameters for the estimation of overweight/obesity. Thus, if only BMI is considered as a parameter for estimation, the prevalence of obesity may be underdiagnosed. From the studies, the parameters such as Waist/height ratio and waist circumference are used for estimation of obesity only and overweight was not included.

The present study also shows a higher prevalence rate of overweight/obesity among girls, as did a previous study done in Chennai [15]. In this study, overweight/obesity is seen slightly increasing with age and their level of study and is more common in boys than girls. From this study, overweight /obesity is seen commonly in students who spend more time in screen viewing such as watching television/mobile phones /computer, and in students who play Indoor games, and in students who don't spend time involved in household activities, and in students who eat non -vegetarian food, and in students who dine out more often, and in students who consume meal frequently, and in students who eat unhealthy snacks (pizza, burger, ice cream, shawarma) and aerated drinks. These were found to be the risk factors predisposing to overweight /obesity in school children

\section{Limitations}

Study population was less and only private school was selected which will have a bias in the nutritional status and socioeconomic of the study population. 


\section{Conclusion}

Overweight and Obesity is an emerging major health problem in school children in our Country. In the present study, it was observed that there is an increased prevalence of overweight /obesity in school children. The factors that influence obesity and overweight are to be prevented by creating awareness programs in school and parents have to be educated about healthy lifestyle management thereby indirectly preventing chronic illness in adulthood

\section{What does the study add to the existing knowledge?}

The present study gives an impact of increasing incidence of overweight and obesity among children which will be a greater impact at a later age which will lead to a burden on the health care system with the increasing incidence of non-communicable disease. Thus changing life study also has contribution which has to have a modification for a healthier society.

\section{Author's contribution}

Dr. Gayathri D.: Concept, study design

Dr. Syamily: Statistical analysis

Dr. M. Kulandaivel: Manuscript preparation

\section{Reference}

01. Kalpana CA, Lakshmi UK. Prevalence of overweight /obesity among school children in Coimbatore city, Tamil Nadu. Int J Curr Res. 2011;3(8)12-16.

doi: $\quad 10.1007 / \mathrm{s} 13312-014-0444-6 \quad$ [Crossref]

02. Shanmugapriya D, Gupta KD, Dharmaraj D. Prevalence of Over-Weight, Obesity and Hypertension in School Going Children \& Their Eating Habits, Chennai, Tamil Nadu, India. IOSR. 2016;15(6)12-15.

doi: $10.9790 / 0853-1506071215$ [Crossref]

03. Harish BR, Asha B, Mahendra BJ. A study of prevalence of obesity among high school children of Mandya city using Waist circumference. Int J Scientific Study. 2014;2(7)107-110.

[Crossref]
04. Kuriyan R. Waist circumference and waist for height percentiles in urban south Indian children aged 3-16 years. Indian Pediatr. $2011 ; 48(10) 765-71$.

doi: $\quad 10.1007 / \mathrm{s} 13312-011-0126-6 \quad$ [Crossref]

05. Patil MA, Rana RR. A comparative study of associated risk factor in normal and overweight children of 12-16 years of age. Int J Contemp Paediatr. 2018;5(3)933-937.

doi: 10.18203/2349-3291.ijcp20181516 [Crossref]

06. Kaushik JS, Narang M, Parakh A. Fast food consumption in children. Indian Pediatr. 2011;48;97-101.

doi: $\quad 10.1007 / \mathrm{s} 13312-011-0035-8 \quad$ [Crossref]

07. Konda SG, Giri PA, Otiv AS. Prevention of overweight and obesity in preschool children- an updated review. Int $\mathrm{J}$ Res Med Sci. 2017;2(3)798-804.

doi: $10.5455 / 2320-6012 . i j r m s 20140801$ [Crossref]

08. Sunder L, Pankaj A. Textbook of Community Medicine-Preventive and Social Medicine. New Delhi- CBS Publication. 2011;3;571-574.

[Crossref]

09. Kishor J. National health programmes of India. New Delhi- Century publications. 2011;9;482. [Crossref]

10. Shanmugam K, Ravishankar SL, Kannappan S, Chacko TV. Prevalence of overweight and obesity among children aged 5-15 years in a rural school in Coimbatore. Int J Med Sci Public Health. 2016;5(11)2186-2189.

doi: $10.5455 /$ ijmsph.2016.21052016487 [Crossref]

11. Prasad RV, Bazroy J, Singh Z. Prevalence of overweight and obesity among adolescent students in Pondicherry, South India. Int J Nutr Pharmacol Neurol Dis. 2016;6(2)72-75. doi: 10.4103/2231-0738.179966 [Crossref]

12. Alice T Cherian, Cherian S, Shobana S. Prevalence of obesity and overweight in Urban school children in kerala ,India. Indian J Pediatr. 2012;49(6)475-477.

[Crossref] 
13. Kotian M, Kumar G, Kotian SS. Prevalence and Determinants of Overweight and Obesity Among Adolescent School Children of South Karnataka. Indian J Comm Med. 2010;35(1)176-178.

doi: $10.4103 / 0970-0218.62587$ [Crossref]

14. Sohani A, Chincholikar S, Patnaik B, Raje S. Obesity Related Indices for Screening of Obesity in Adolescents. Indian J Community Health. 2015;27(3)304-10.

Available from: [Article] [Crossref]

15. Tharkar S, Viswanathan V, Thomas O. Impact of socioeconomic status on prevalence of overweight and obesity among children and adolescents in urban India. Open Obesity J. 2009;1(1).

[Crossref] 